\title{
The contribution of general practice and the general practitioner to NHS patients
}

\author{
Tim Wilson ${ }^{1}$ Martin Roland ${ }^{2}$ Chris $\mathrm{Ham}^{3}$
}

J R Soc Med 2006;99:24-28

\section{BACKGROUND}

The English Department of Health is currently shining the spotlight of health service reform on primary care, particularly general practice, in the form of a white paper on Health outside Hospitals. In essence the Department is heralding the introduction of competition into general practice, especially in under doctored areas, with the aim of offering patients a choice of practice and to introduce market forces into general practice provision., ${ }^{1,2}$ This follows hard on the heels of a completely new contract for general practice, introduced in April 2004, which probably represents the most ambitious pay for performance contract seen in health care anywhere in the world. ${ }^{3}$

Given this background, the authors use this article to reappraise the current evidence regarding general practice within the UK National Health Service (NHS), reflecting on its contribution, inherent advantages and shortcomings.

\section{INTRODUCTION}

In an era of dissatisfaction with many public services, the strength of British primary care, and especially general practice, leads other countries to look enviously at the UK. ${ }^{4,5}$ We can say, with some certainty, that healthcare systems which are oriented towards primary care generally produce high quality, equitable and efficient care. ${ }^{6}$ In this article we assess how well this holds true in the NHS and in reviewing the evidence describe where there might be weaknesses in British general practice. We think that British general practice should be measured against four dimensions:

- equity

- quality of clinical care

- responsiveness to patients

- efficiency

${ }^{1}$ General Practitioner, Mill Stream Surgery, Benson, Wallingford, Oxon OX10 6RL; ${ }^{2}$ Director, National Primary Care R\&D Centre, University of Manchester, Manchester; ${ }^{3} \mathrm{Health}$ Services Management Centre, University of Birmingham, Birmingham, UK

Correspondence to: Dr Tim Wilson and that there are three important characteristics that contribute to this success:

- coordination

- continuity

- comprehensiveness

\section{EQUITY}

Compared to other healthcare systems the NHS does well in respect of equity; ${ }^{7}$ the ability to provide healthcare in relation to the need of the whole population. The reason for this is partly because having the whole population registered with a strong primary care service improves equitable access. In contrast, healthcare systems that are orientated towards specialist care tend to reinforce inequalities in access. ${ }^{8}$ The absence of financial barriers to primary care contributes to equity and means that patients in the UK are least likely to report that they do not use services because of the cost of care. ${ }^{9}$

There are some notable recent achievements in providing equitable care in the NHS. For example, Figure 1 shows the proportion of practices in affluent and deprived areas achieving the target of over $80 \%$ of eligible women having received a cervical smear. Showing not only that overall rates are high and have increased since 1990, but that there has been progressive narrowing of the difference between affluent and deprived districts since $1990 . .^{10}$ Similar narrowing in the social gradient for childhood immunization is seen in this period. ${ }^{11}$

These improvements in equitable care have, arguably, been one-off improvements through a target-based approach. Indeed, when looked at more broadly, the aim of providing equitable care across the UK is not perfectly realized for all population groups. For example, women and people from ethnic minorities may receive worse care for coronary heart disease compared to men and Caucasians. ${ }^{12,13}$ The challenge for general practice is to realize the potential of the registered population and to narrow the gap between affluent and deprived for other aspects of health. ${ }^{14}$ While good access to primary care appears to minimize the effects of health inequalities, ${ }^{15}$ the inverse care law still applies to the distribution of general practice in the UK, so that those areas which are in greatest 


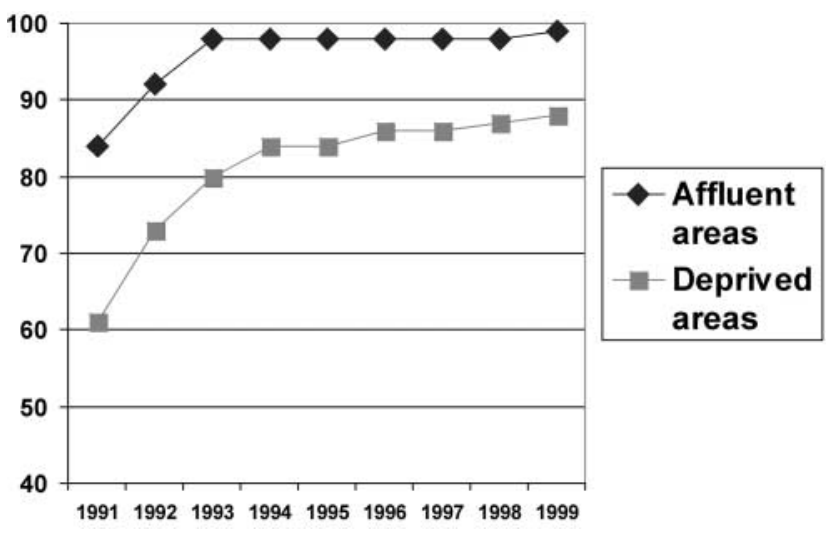

Figure 1 Percentage of UK general practices reaching $80 \%$ target of eligible women receiving cervical cytology (derived from data in Ref. 10)

need are may have least resource. These inequalities have got worse in recent years. ${ }^{16}$ This is mainly because in Britain no successful solution has been found by policy makers and general practice leaders, although there is extensive experience from other countries of strategies that can be used to improve the supply of doctors in underserved areas. ${ }^{17}$

\section{QUALITY OF CLINICAL CARE}

Significant strides have been made in improving quality of clinical care in general practice in the UK; the care provided now bears little relation to that provided a few years ago. ${ }^{18,19}$ These changes can be attributed to the development of clinical audit, to the gradual acceptance of the role of role of evidence based practice (e.g. the use of clinical guidelines) in certain areas of practice and, in some cases, the targeting of resources towards improving quality of care. ${ }^{20-22}$ However, more detailed analyses of the processes of care reveal that there are substantial gaps, with wide variation in the quality of care, especially for chronic diseases. ${ }^{23}$

The recent emphasis on access as an integral part of quality of care has focused on waiting times. The government's challenging targets of access to a health professional within 24 hours, and access to a general practitioner within 48, have ostensibly been met. ${ }^{24}$ However, an over-rigid approach to providing 48-hour access means that in many areas patients now have difficulty in booking appointments at a convenient time ahead. ${ }^{25}$ Patient expectations are very high in terms of being able to be seen rapidly, but many also expect high standards of continuity of care. ${ }^{26}$

\section{RESPONSIVENESS TO PATIENTS}

Patient surveys in the UK indicate high levels of satisfaction with primary care while also identifying areas for improvement, especially around patient responsiveness. We suspect that patient satisfaction has been enhanced by the changing pattern of general practice with increasing numbers of GPs, longer consultation times, and increased use of the wider primary care team. Significant weaknesses identified in recent surveys included scope for better patient involvement in decisions about care and treatment, particularly decisions about medication and information about side effects. These results were confirmed by a survey of patient experience of primary care in five countries that reported the UK performing worse than other countries in relation to information about medicines, shared decision making, patients' access to records, preventive advice, and self management of chronic disease.

\section{EFFICIENCY}

A study involving 11 developed countries, demonstrated that higher primary care orientation was associated with markedly reduced cost (Figure 2). ${ }^{27}$ As the figure shows, the UK had one of the lowest costs and a high orientation towards primary care. A systematic review of accident and emergency care suggests that broadening access to general practice reduces demand for more expensive, specialist-led hospital care. ${ }^{28}$ This type of analysis has proved highly influential among policymakers and healthcare funders, although shifting resources away from hospitals to primary care often lags behind policy intent.

\section{CO-ORDINATION, CONTINUITY, COMPREHENSIVENESS}

Why do primary-care orientated health systems deliver higher quality clinical care, with high levels of satisfaction, whilst more efficiently and equitably? We believe there are three characteristics that above all others contribute to this success: co-ordination, continuity and comprehensiveness.

\section{Coordination of care}

The presence of the registered list confers an advantage on the NHS's potential to coordinate patients' care in the community. Coordination of care becomes increasingly important as the population ages and the prevalence of comorbidity increases. Such co-morbidity occurs disproportionately within populations that are socio-economically disadvantaged or elderly, and particularly within populations which are both. ${ }^{29,30}$ Hospitals, which are designed for acute episodic care, find it increasingly difficult to meet and co-ordinate the complex needs of these patients. ${ }^{31,32}$

Within primary care, general practice teams often pride themselves on providing effective team care. Indeed, coordinated team-working is one of the most consistent predictors of quality of care across a range of aspects of practice. ${ }^{33}$ With a large divide between primary and 


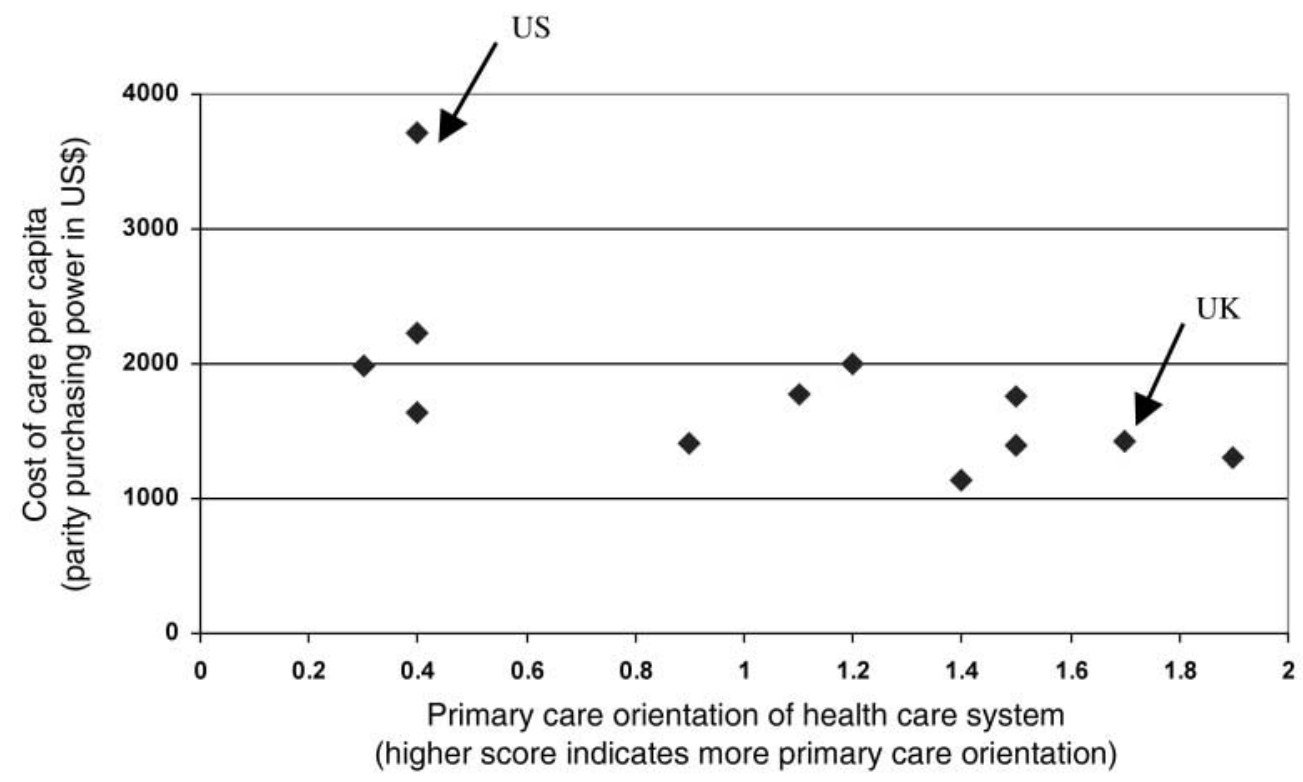

Figure 2 Relationship between costs of health care and primary care orientation in twelve developed countries (derived from data in Ref. 27)

secondary care as exists in the NHS, ensuring coordinated care across boundaries is an important aspect of the GP's work, perhaps more than ever as hospital departments become increasingly specialized, with reducing opportunities for anyone other than the GP to have a complete overview of the patient's care.

\section{Continuity of care}

Long-term personal continuity is perhaps most central to the ethos of British general practice. There is little doubt about the benefits of continuity in certain circumstances. Having a doctor who is known and trusted is highly valued by patients especially when they have serious or psychological problems. ${ }^{34}$ For doctors a long-term relationship makes both diagnosis and care easier. ${ }^{35-37}$ Continuity of care increases understanding between doctor and patient, may increase compliance, and may also reduce the opportunity for medical errors to be made. ${ }^{38,39}$

Despite these benefits, the NHS model of the individual GP offering continuity to individual patients, sometimes 24 hours a day and 7 days a week, has changed markedly in recent years. ${ }^{40}$ This is partly the result of developments within practices (e.g. larger teams, more delegation and increased part time working) and partly the result of developments outside practice (e.g. the arrival of new points of contact with the NHS such as NHS Direct, and walk in centres). Of particular importance has been the development in out-of-hours-services, notably with the start of the arrangements whereby GPs started to work together in larger cooperative groups. This change has more difficult and, of course, has been enshrined by the new GP contract which has seen large numbers of GPs voluntarily relinquish their out of hours duties.

\section{Comprehensive care}

International comparisons are of interest; compared to primary care physicians in other countries, UK GPs provide a less comprehensive service. In the USA, for example, providing in-patient care and maternity care have recently been defined as core elements of the work of a family practitioner, ${ }^{41}$ and many have admitting rights to local hospitals (though they are also concerned that the scope of their work is too broad ${ }^{42}$ ). In rural countries like Australia, GPs provide a wide range of services that that would rarely be seen in UK primary care. In comparison to other European countries, the UK GPs are more extensively involved in chronic disease management, but less involved in health education than in most countries. ${ }^{43}$

The range and scope of services offered by practices has changed markedly over the years. For example, hypertension was previously the provenance of the specialist but is now a condition which specialists only treat in its malignant or rare forms. Patients prefer a comprehensive service close to their home with that service being provided by their general practice with input, if appropriate, from a specialist.

\section{CONCLUSION: THE FUTURE}

General practice has changed with the times. The development of group practices and primary care teams, the provision of more services in primary care, the reduction in list sizes, the increase in consultation times, 
and the reduction in the time patients wait to see a GP or other primary care professional testify to the changes that have occurred in recent years. Despite these changes, many would argue that general practice in Britain has been slow to adapt to social changes. Patient responsiveness is arguably the weakest aspect of general practice and might be getting worse with restriction in opening times. In particular, the ability of British general practice to meet patients' expectations of greater involvement in their own care appears to lag behind other countries. Further, despite many improvements in the quality of care in general practice, problems remain. Finally, although contributing to improvements in equitable healthcare, some groups appear to lose out, either through the poor delivery of care or problems of access to a local practice.

Looking to the future, British general practice will have to adapt to the demands of the government for continuing improvements in equity, efficiency, clinical quality and patient responsiveness, and to the expectations of the staff delivering primary care for work that is both stimulating and manageable alongside other commitments. We believe that one way of squaring the circle would be for GPs to make greater use of the wider primary care team, including nurses, pharmacists and allied health professionals, thereby enabling doctors to focus on what they can do best, such as the assessment and management of poorly differentiated symptoms. Whether current reforms, designed to introduce choice and competition into general practice, will deliver benefits is less certain; or to be more precise, whether the probable improvements in some aspects of general practice (e.g. responsiveness) might be at the expense of problems in other areas (e.g. equity) remains to be seen.

Acknowledgments This paper is based in part on discussions which took place within The Future of General Practice group established by the Royal College of General Practitioners, of which TW and MR were members. We would like to thank the convenor, David Haslam, and other members, Richard Baker, Bonnie Sibbald, Martin Marshall, David Colin-Thorne, Kieran Sweeney, Maureen Baker, Iona Heath, Susannah Graham-Jones and Hilary De Lyon for their contributions to these discussions. The views expressed represent those of the authors and not necessarily those of the group, or the authors' employing organizations.

Competing interests TW and MR are GPs and are likely to be affected by policy changes in general practice. MR and $\mathrm{CH}$ both receive grants from the $\mathrm{DoH}$ and other bodies to study policy changes, including those in primary care. TW and $\mathrm{CH}$ do management consultancy that advises the $\mathrm{DoH}$ and others on primary care policy. All three authors have received fees and expenses for speaking on primary care policy.

\section{REFERENCES}

1 Department of Health. More GPS For Under Doctored Areas. Press release 26 July 2005. 2005/0267 [www.dh.gov.uk/PublicationsAndStatistics/ PressReleases/fs/en] Accessed 12 September 2005

2 Marshall M, Wilson T. Competition in general practice. BMJ 2005;331: 1196-9

3 Roland M. Linking physicians' pay to the quality of care-a major experiment in the United Kingdom. N Engl J Med 2004;351:1448-54

4 De Maeseneer J, Hjortdahl P, Starfield B. Fix what's wrong, not what's right, with general practice in Britain. BMJ 2000;320:1616-17

5 Grol R, Leatherman $S$. Improving quality in British primary care: seeking the right balance. Br J Gen Pract 2002;52(suppl):S3-4

6 Starfield B, Shi L, Macinko J. Contribution of primary care to health systems and health. Milbank $Q$ 2005;83:457-502

7 Blendon RJ, Schoen C, DesRoches CM, Osborn R, Scoles KL, Zapert $\mathrm{K}$. Inequities in health care: a five-country survey. Health Affairs 2002;21:182-91

8 Weiner J, Starfield B. Measurement and the primary care roles of office based physicians. Am J Public Health 1983;73:666-71

9 Schoen C, Osborn R, Huynh PT, et al. Primary care and health system performance: adults' experiences in five countries [web exclusive]. Health Affairs 2004 [http:/ / content.healthaffairs.org/cgi/content/full/ hlthaff.w4.487/DC1]

10 Baker D, Middleton E. Cervical acreening and health inequality in England in the 1990s. J Epidemiol Commun Health 2003;57:417-23

11 Middleton E, Baker D. Comparison of social distribution of immunisation with measles, mumps, and rubella vaccine, England, 1991-2001. BMJ 2003;326:854

12 Gatrell A, Lancaster G, Chapple A, Horsley S, Smith M. Variations in use of tertiary cardiac services in part of North-West England. Health Place 2002;8:147-53

13 Bowling A, Bond M, McKee D, et al. Equity in access to exercise tolerance testing, coronary angiography, and coronary artery bypass grafting by age, sex and clinical indications. Heart 2001;85:680-6

14 Williams R. Motherhood, Apple Pie, and COPC. Ann Fam Med 2004;2100-2

15 Shi L, Macinko J, Starfield B, Wulu J, Regan J, Politzer R. The relationship between primary care, income inequality, and mortality in US States, 1980-1995. J Am Board Fam Pract 2003;16:412-22

16 Hann M, Gravelle $\mathrm{H}$. The maldistribution of general practitioners in England and Wales 1974-2003. Br J Gen Pract 2004;54:894-8

17 Sibbald B. Putting general practitioners where they are needed: an overview of strategies to correct maldistribution. National Primary Care Research and Development Centre October 2005. Available at: [www.npcrdc.man.ac.uk/Publications/overview $\% 20$ of $\% 20$ strategies $\% 20$ to\%20correct $\% 20$ maldistribution.pdf]

18 Baker R, Roland M. General practice: continuous quality improvement since 1948. Br J Gen Pract 2002;52 (suppl):S2-3

19 Campbell S, Roland M, Middleton E, Reeves D. Improvements in quality of clinical care in English general practice 1998-2003: longitudinal observational study. BMJ 2005;331:1121

20 Campbell S, Steiner A, Robison J, Webb D, Raven A, Roland M. Is the quality of care in general medical practice improving? Results of a longitudinal observational study. Br J Gen Pract 2003;53:298-304

21 Spooner A, Chapple A, Roland M. What makes British general practitioners take part in a quality improvement scheme? J Health Serv Res Policy 2001;6:145-50

22 Campbell SM, Robison J, Steiner A, Webb D, Roland MO. Improving the quality of mental health services in Personal Medical Services 
pilots: a longitudinal qualitative study. Qual Safety Health Care 2004; 13:115-20

23 Seddon, ME, Marshall MN, Campbell SM, Roland MO. Systematic review of studies $f$ quality of clinical care in general practice in the UK, Australia and New Zealand. Qual Health Care 2001;10:152-8

24 Crisp N. Chief Executives Report to the NHS December 2004. [http: / /www.dh.gov.uk/assetRoot/04/09/73/76/04097376.pdf] Accessed March 2005

25 Commission for Health Improvement Local Health Services Patient Survey 2003 [http://www.chi.nhs.uk/eng/surveys/ nps2003/pct_leaflet.pdf] Accessed March 2005

26 Bower P, Roland M, Campbell J, Mead N. Setting standards based on patients' views on access and continuity: secondary analysis of data from the general practice assessment survey. BMJ 2003;236: $258-60$

27 Starfield B. Primary Care. Balancing Health Needs, Services And Technology. New York, Oxford University Press, 1998

28 Roberts E, Mays N. Can primary care and community-based models of emergency care substitute for the hospital accident and emergency department? Health Policy 1998,44:191-214

29 Menotti A, Mulder I, Nissinen A, Giampaoli S, Feskens EJ, Kromhout D. Prevalence of morbidity and multimorbidity in elderly male populations and their impact on 10-year all-cause mortality: The FINE study (Finland, Italy, Netherlands, Elderly). J Clin Epidemiol 2001;54:680-6

30 Watt G. The inverse care law today. Lancet 2002;360:252-4

31 World Health Organization. Innovative Care for Chronic Conditions: Building Blocks for Action, Global Report May 2002 [www.who.int/ chronic_conditions] Accessed 15.4.04

32 Kane RL. Clinical challenges in the care of frail older persons. Aging Clin Exp Res 2002;14:300-6
33 Campbell SM, Hann M, Hacker J, et al. Identifying predictors of high quality care in English general practice: observational study. BMJ 2001;323:784-7

34 Kearley KE, Freeman G, Heath A. An exploration of the value of the personal doctor-patient relationship in general practice. Br J Gen Pract 2001;51:712-18

35 Pereira Gray D, Evans P, Sweeney K, Lings P, Seamark D, Seamark C. Towards a theory of continuity of care. JRSM 2003;96:160-6

36 Manious AG, Baker R, Love M, Pereira Gray DJ, Gill JM. Continuity of care and trust in one's physician: evidence from primary care in the US and UK. Fam Med 2001;33:22-7

37 Hjortdahl P, Borchgrevink CF. Continuity of care: influence of general practitioner's knowledge about their patients on use of resources in consultations. Br J Gen Prac 2003;53:798-800

38 Freeman G, Hjortdahl P. What future for continuity of care in general practice? BMJ 1997;314:1870-3

39 Dovey SM, Meyers DS, Phillips RL Jr, et al. A preliminary taxonomy of medical errors in family practice. Qual Saf Health Care 2002;11: 233-8

40 Haggerty JL, Reid RJ, Freeman GK, Starfield BH, Adair CE, McKendry R. Continuity of care: a multidisciplinary review. BMJ 2003;327:1219-21

41 Future of Family Medicine Leadership Committee. The future of family medicine: a collaborative project of the Family Medicine Community. Ann Fam Med 2004;2(suppl):S3-32

42 St Peter RF, Reed MC, Kemper P, Blumenthal D. Changes in the scope of care provided by primary care physicians. N Engl J Med 1999; 341:1980-5

43 Grielen SJ, Boerma WGW, Groenewegen PP. Unity or diversity? Task profiles of general practitioners in central and eastern Europe. Eur J Public Health 2000;10:249-54 